\title{
Haloperidol blocks reacquisition of operant running during extinction following a single priming trial with food reward
}

\author{
JENNY L. WILEY, JOSEPH H. PORTER, and WILLIAM R. FAW \\ Virginia Commonwealth University, Richmond, Virginia
}

\begin{abstract}
In the present experiment, we examined the anhedonic effects of the neuroleptic haloperidol in an alleyway reacquisition procedure consisting of four consecutive phases: acquisition, extinction, drug injection, and testing. After acquisition training to traverse a straight alleyway for 1045 -mg food pellets (single trial/day), food-deprived rats ( $n=8 /$ group) were tested without food reward until running times met an extinction criterion. Then, a single priming trial with food reward was conducted with four groups receiving $0.033,0.10$, or $0.30 \mathrm{mg} / \mathrm{kg}$ of haloperidol or vehicle $(V+F)$ injections. A fifth group $(V+E)$ received vehicle injections but no food reward. The test-day trial was given $24 \mathrm{~h}$ after the injection-day trial. The last three phases of the experiment were repeated. The results indicated that the food prime resulted in faster test-day running times for the $\mathrm{V}+\mathrm{F}$ group; however, haloperidol attenuated this reacquisition effect. Since haloperidol is a relatively specific dopamine blocker, the results support the suggestion that brain dopamine systems are involved in reward.
\end{abstract}

An effect of neuroleptic administration that has been reliably observed in experimental research with animals is the suppression of operant behavior. Neuroleptics have been shown to decrease the frequency of behaviors maintained by a variety of positive reinforcers, including food (Phillips \& Fibiger, 1979), water (Gramling \& Fowler, 1985), and electrical stimulation of the brain (Franklin \& McCoy, 1979). The mechanism for this effect, however, remains unclear. Of the several hypotheses proposed to account for neuroleptic-induced disruption of operant behavior, the motor-deficit hypothesis and the anhedonia hypothesis have received the majority of research attention. Whereas the motor-deficit hypothesis (e.g., see Ahlenius, 1979; Fibiger, Carter, \& Phillips, 1976) attributes response-rate decreases to the motor effects of neuroleptics, the anhedonia hypothesis (Wise, 1982) suggests that neuroleptics reduce the reinforcement efficacy of reward. Both hypotheses, however, predict the same result: the suppression of operant behavior maintained by positive reinforcement. Since in most studies animals have been tested while they were drugged, the separation of the motor effects of neuroleptics from the anhedonic effects has been difficult.

Ettenberg and Horvitz (1987) have reported results of an alleyway procedure that permits the testing of the anhedonic effects of neuroleptic drugs without the confound of motor effects. An alleyway reacquisition procedure was used, in which drug treatment and the behavioral test trial occurred on different days. This allowed the motivational

Reprint requests should be sent to Joseph H. Porter, Department of Psychology, Box 2018, Virginia Commonwealth University, Richmond, VA 23284-2018. effects of the neuroleptic haloperidol to be assessed without the confound of motor effects during testing. The present study represents a replication and an extension of their study. It differs from the Ettenberg and Horvitz study in that two lower doses of haloperidol were tested, and in that the entire procedure was replicated with the same animals.

\section{METHOD}

\section{Subjects and Apparatus}

Forty adult male Sprague-Dawley rats served as subjects. The rats were individually housed in wire cages, in a temperature-controlled $\left(22^{\circ} \mathrm{C}\right)$ environment with a 12:12-h light:dark cycle (lights on at 6 a.m.). Throughout the experiment, the rats were maintained on a food-restricted diet at $80 \%$ of their free-feeding body weights; they had free access to water in their home cages.

The apparatus consisted of a straight-arm alleyway $(150 \times 15.5 \times$ $18.5 \mathrm{~cm})$ with attached start- $(21.5 \times 21.5 \mathrm{~cm})$ and goal $-(25.5 \times 21 \mathrm{~cm})$ boxes. The start- and goalboxes had manually operated guillotine doors. Lifting the startbox door triggered a switch that started the first sweep timer (Lafayette Instruments, model 54014). Interruption of an infrared photocell beam in the alleyway $(13 \mathrm{~cm}$ from startbox door) simultaneously stopped the first timer and started a second one. The second timer stopped when the rat interrupted a photo-cell beam located in the goalbox ( $7.5 \mathrm{~cm}$ from the door). The first timer recorded latency (in sec) to leave the startbox (start latency); the second, latency (in sec) to arrive at the goalbox (goal latency).

\section{Procedure}

Throughout the entire experiment, the animals received one trial per day in the alleyway. On the first 2 days of adaptation, each rat was placed in the goalbox (with the door in place), with five 45-mg BioServe rodent pellets in the food cup. The rat remained in the goalbox until all the pellets were eaten or for $5 \mathrm{~min}$. By Day 2, all the rats ate all of the food pellets. On the 3rd day of adaptation, 10 food pellets were placed in the food cup, and each rat was placed in the goalbox. Following adaptation, the experimental protocol consisted of four consecutive phases: 
Table 1

Mean Total Running Times (in sec) for Acquisition Baseline, Including SEMs, and Mean Number of Trials, Including Ranges, for Acquisition and Both Extinction Phases for Each Group

\begin{tabular}{|c|c|c|c|c|c|c|c|c|}
\hline \multirow[b]{2}{*}{ Group } & \multicolumn{2}{|c|}{$\begin{array}{l}\text { Acquisition } \\
\text { Baseline }\end{array}$} & \multicolumn{2}{|c|}{ Acquisition } & \multicolumn{2}{|c|}{ Extinction 1} & \multicolumn{2}{|c|}{ Extinction 2} \\
\hline & Running Time & SEM & Trials & Range & Trials & Range & Trials & Range \\
\hline $\mathrm{V}+\mathrm{F}$ & 4.85 & .49 & 8.9 & $5-19$ & 9.1 & $5-14$ & 6.1 & $3-11$ \\
\hline$V+E$ & 5.11 & .60 & 8.9 & $5-23$ & 6.8 & $4-12$ & 4.4 & $3-13$ \\
\hline $.30 \mathrm{H}$ & 4.95 & .52 & 9.4 & $5-23$ & 8.6 & $5-17$ & 5.0 & $3-18$ \\
\hline $.10 \mathrm{H}$ & 5.23 & .52 & 6.9 & $5-15$ & 8.6 & $5-10$ & 9.3 & $3-19$ \\
\hline $.03 \mathrm{H}$ & 5.44 & .69 & 6.4 & $5-15$ & 8.4 & $5-13$ & 5.9 & $3-15$ \\
\hline
\end{tabular}

acquisition, extinction, drug injection, and testing. Each trial consisted of placing the rat in the startbox and opening the startbox door, followed by the rat's traversing the alleyway, entering the goalbox, and consuming any available food reward. The start- and goalbox doors were closed subsequent to the animal's passing, in order to prevent retracing. Start and goal latencies (in sec) were recorded for each trial. The animals were allowed a maximum of 10 min of running time (start- and goal-latency maximums of $5 \mathrm{~min}$ each) to complete each trial. Animals not exiting the startbox or entering the goalbox within the 5-min maximum were placed manually in the alleyway or the goalbox, respectively.

During the acquisition phase, the rats traversed the alleyway and, upon reaching the goalbox, they were allowed to consume a reward of 10 food pellets. The criterion for acquisition consisted of three consecutive trials in which each trial had a total running time of less than $10 \mathrm{sec}$ (minimum of five trials). An animal's mean running time for the three acquisition-criterion trials constituted its acquisition baseline. On the day after the final acquisition trial, the extinction phase began. The extinction trials were identical to the acquisition trials, except that the food cup in the goalbox was empty. The extinction criterion consisted of three consecutive trials in which each trial's running time was more than three times the animal's acquisition baseline. The extinction baseline was calculated as the mean of the animal's running times during the three extinction-criterion trials.

On the day after each rat's final extinction trial, the drug-injection trial was conducted. The rats were matched according to acquisitionbaseline running times and assigned to one of the following five experimental conditions $(n=8)$ for the injection-day trial:

1. VEH + FOOD $(\mathrm{V}+\mathrm{F})$ : The animals received a vehicle injection 45 min before being placed in the baited alleyway.

2. VEH + EXTINCTION $(V+E)$ : The animals received a vehicle injection $45 \mathrm{~min}$ before being placed in the unbaited alleyway.

3. HAL $.30+$ FOOD $(.30 \mathrm{H})$ : The animals received an injection of haloperidol $(0.30 \mathrm{mg} / \mathrm{kg}) 45 \mathrm{~min}$ before being placed in the baited alleyway.

4. HAL .10 + FOOD $(.10 \mathrm{H})$ : The animals received an injection of haloperidol $(0.10 \mathrm{mg} / \mathrm{kg}) 45 \mathrm{~min}$ before being placed in the baited alleyway.

5. HAL .033 + FOOD $(.03 \mathrm{H})$ : The animals received an injection of haloperidol $(0.033 \mathrm{mg} / \mathrm{kg}) 45 \mathrm{~min}$ before being placed in the baited alleyway.

On the test day ( $24 \mathrm{~h}$ after the injection-day trial), all the animals were given a nonrewarded trial in the alleyway. Following the test-day trial, the last three phases of the experiment (i.e., extinction, injection, and testing) were repeated for each rat.

The haloperidol $(0.30,0.10$, and $0.033 \mathrm{mg} / \mathrm{ml})$ was prepared using a vehicle solution of $85 \%$ lactic acid (5-10 drops) and distilled water. The injections of haloperidol and vehicle were administered intraperitoneally at a volume of $1 \mathrm{ml} / \mathrm{kg}$ of body weight.

\section{RESULTS}

Table 1 lists the means and SEMs for the total running times (start latencies plus goal latencies) during the acquisition baseline, and the mean numbers of trials, along with their ranges, for the acquisition and both extinction phases (1 and 2). The means, which are listed separately for each experimental condition, are similar for all the groups.

For the purposes of data analysis, the start and goal latencies were combined to yield total running times (in seconds). Then the running times were converted to reciprocals $(1 / \mathrm{sec})$ in order to control for heterogeneity of variance (see Box, Hunter, \& Hunter, 1978). Since an initial repeated measures ANOVA on reciprocals for the two extinction baselines and the 2 test days did not reveal any significant differences between the first run and the replication, the data from the first run and the replication were combined for further analysis.

Figure 1 shows the mean reciprocals $(+S E M)$ for the combined extinction baselines and test days, for each experimental condition. A split-plot ANOVA revealed significant main effects for experimental conditions $[F(4,35)=3.00, p<.05]$ and trials $[F(1,35)=32.00$, $p<.001]$ and a significant interaction $[F(4,35)=3.00$, $p<.05$ ]. Duncan's post hoc tests $(p=.05)$ showed that none of the haloperidol groups differed significantly from the $\mathrm{V}+\mathrm{E}$ group. The $\mathrm{V}+\mathrm{F}$ group, however, ran significantly faster than did the $\mathrm{V}+\mathrm{E}$ and the $.3 \mathrm{H}$ groups. Within-subject comparisons across trials revealed that the $\mathrm{V}+\mathrm{F}, .30 \mathrm{H}, .10 \mathrm{H}$, and $.03 \mathrm{H}$ groups each ran significantly faster on the test day than during extinction.

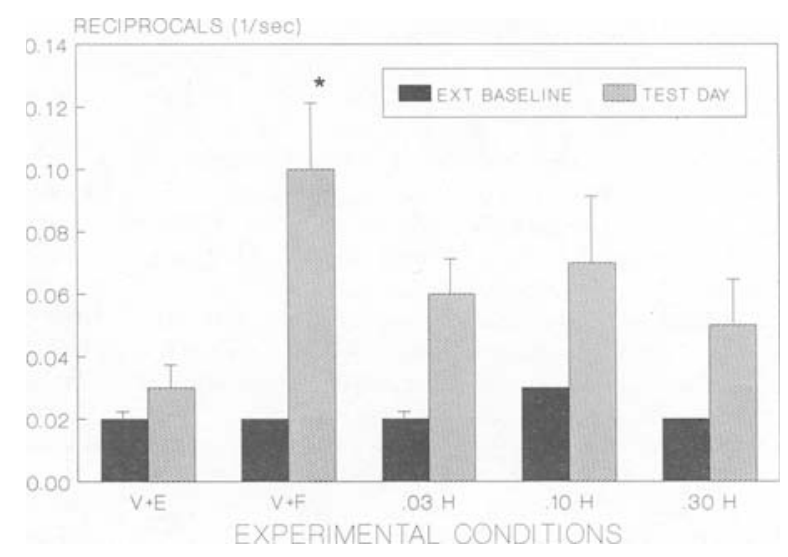

Figure 1. Mean reciprocals $(+S E M)$ for the combined extinction baselines and test days for each experimental condition. The asterisk indicates significant difference $(p<.05)$ from the $V+E$ group. 


\section{DISCUSSION}

The results of the present study demonstrated that a single foodrewarded trial was sufficient for rats to reacquire operant running while being tested in an alleyway procedure under extinction conditions. The animals receiving vehicle injections plus food $(V+F)$ on the injection day ran significantly faster on the following test day than did the animals that received the vehicle injection but did not have any food reward $(\mathrm{V}+\mathrm{E})$ during the injection-day trial. All three doses of haloperidol $(0.033,0.10$, and $0.30 \mathrm{mg} / \mathrm{kg})$ disrupted this reacquisition effect. Even though the haloperidol-injected rats received a food reward for running the alleyway on the injection day, their running did not differ significantly from that of the nonrewarded vehicle group $(V+E)$. Furthermore, the rats that received $0.30 \mathrm{mg} / \mathrm{kg}$ haloperidol ran significantly slower than did the rewarded vehicle rats $(V+F)$ on the test day.

These results replicate those reported by Ettenberg and Horvitz (1987). They demonstrated that 0.15 and $0.30 \mathrm{mg} / \mathrm{kg}$ doses of haloperidol blocked the reacquisition of operant running following a single foodrewarded trial during extinction. The present study showed that this reacquisition effect could be blocked by even lower doses of haloperidol $(0.033$ and $0.10 \mathrm{mg} / \mathrm{kg})$. There was no evidence of a dose-related effect in either study, however, which suggests that even lower doses of haloperidol should be tested in this paradigm. The results of the present study also showed that the effects of haloperidol did not change with a second injection trial and subsequent test trial. Thus, there was no evidence of any tolerance or sensitization over two injection trials.

A number of different hypotheses may be proposed to explain the disruption produced by haloperidol in this reacquisition paradigm. The motor-deficit hypothesis (Ahlenius, 1979; Fibiger et al., 1976) would support the argument that residual motor effects from the previous day's injection of haloperidol could have produced slower test-day running times. This seems unlikely, however, since Ettenberg and Horvitz (1987) included a control group that received $0.30 \mathrm{mg} / \mathrm{kg}$ of haloperidol following a food-rewarded trial. On the subsequent test day, these animals demonstrated a reacquisition of running similar to that seen with foodrewarded rats that had received a vehicle injection. Ettenberg and Horvitz also tested for possible state-dependent effects (Overton, 1978) in this paradigm, and they concluded that state-dependent learning could not account for the results obtained in their study.

The results of the present study and the study by Ettenberg and Horvitz (1987) may be cited as evidence supporting the anhedonia hypothesis of neuroleptic suppression of operant behavior (Wise, 1982). If typical neuroleptics such as haloperidol reduce the rewarding efficacy of food (and other positive reinforcers), subsequent behavior of drugged animals would be expected to resemble that of animals receiving rewards of lesser magnitude or no reward at all. The results of the present experiment are consistent with this interpretation, in that the running times of the rats injected with haloperidol did not differ significantly from the running times of the nonrewarded rats that received vehicle injections $(V+E$ group).

Other behavioral paradigms in which animals were not drugged during behavioral testing have also provided support for an anhedonic interpretation of neuroleptic action on operant behavior. It has been shown that intermittent administration of haloperidol produced a partialreinforcement extinction effect, comparable to periodic reward omission, in animals continuously reinforced with food (Ettenberg \& Camp, 1986a), or water (Ettenberg \& Camp, 1986b), during acquisition of an alleyway task. Similarly, Duvauchelle and Ettenberg (1987) reported that haloperidol blocked the conditioned place preference induced by rewarding brain stimulation. Thus, haloperidol has been found to reduce the hedonic value of several different positive reinforcers in a variety of experimental procedures.

In summary, this alleyway procedure offers an important advantage over many of the other procedures used to study neuroleptics, in that behavioral testing is conducted in the absence of the drug. Thus, the effects of neuroleptics on operant behavior can be examined without the influence of motor side effects. The results of the present study suggest that haloperidol can attenuate the incentive motivational properties of food reinforcement. Haloperidol does not, however, totally eliminate the reward value of food, as is demonstrated by two findings: first, all the food pellets were consumed by the rats injected with haloperidol on the injection days; and second, the haloperidol groups ran significantly faster on the test day than they did during the extinction baseline. Finally, since the only known common property of neuroleptics is dopamine antagonism (Carlsson, 1977; Niemegeers \& Leysen, 1982), the reduction of reward efficacy produced by injection with neuroleptic drugs such as haloperidol suggests that brain dopamine systems are involved in reward.

\section{REFERENCES}

Ahlenius, S. (1979). An analysis of behavioral effects produced by drug-induced changes in dopaminergic neurotransmission in the brain. Scandinavian Journal of Psychology, 20, 59-64.

Box, G. E. P., Hunter, W. G., \& Hunter, J. S. (1978). Statistics for experimenters. New York: Wiley.

Carlsson, A. (1977). Does dopamine play a role in schizophrenia? Psychological Medicine, 7, 583-597.

Duvauchelle, C. L., \& ETtenberg, A. (1987). Haloperidol blocks conditioned place preferences induced by rewarding lateral hypothalamic stimulation in rats. Society for Neuroscience Abstracts, 13, 1323. (Abstract)

ETtENBERG, A., \& CAMP, C. H. (1986a). Haloperidol induces a partial reinforcement effect in rats: Implications for dopamine involvement in food reward. Pharmacology, Biochemistry \& Behavior, 25, 813-821.

EtTEnberG, A., \& CAMP, C. H. (1986b). A partial reinforcement extinction effect in water-reinforced rats intermittently treated with haloperidol. Pharmacology, Biochemistry \& Behavior, 25, 1231-1235.

ETTENBERG, A., \& HoRviTz, J. (1987). Haloperidol blocks the incentive motivational properties of food reinforcement in rats. Society for Neuroscience Abstracts, 13, 219. (Abstract)

Fibiger, H. C., Carter, D. A., \& Phillips, A. G. (1976). Decreased intracranial self-stimulation after neuroleptic or 6-hydroxydopamine: Evidence for mediation by motor deficits rather than by reduced reward. Psychopharmacology, 47, 21-27.

Franklin, K. B. J., \& McCoy, S. N. (1979). Pimozide-induced extinction in rats: Stimulus control of responding rules out motor deficit. Pharmacology, Biochemistry \& Behavior, 11, 71-75.

Gramling, S. E., \& Fowler, S. C. (1985). Effects of neuroleptics on rate and duration of operant versus reflexive licking in rats. Pharmacology, Biochemistry \& Behavior, 22, 541-545.

Niemegeers, C. J. E., \& LeYSEN, J. E. (1982). The pharmacological and biochemical basis of neuroleptic treatment in schizophrenia. Pharmaceutisch Weekblad, Scientific Edition, 4, 71-78.

OVERTON, D.A. (1978). Major theories of state dependent learning. In B. T. Ho, D. W. Richards, \& D. L. Chutes (Eds.), Drug discrimination and state dependent learning (pp. 283-318). New York: Academic Press.

Phillips, A. G., \& Fibiger, H. C. (1979). Decreased resistance to extinction after haloperidol: Implications for the role of dopamine in reinforcement. Pharmacology, Biochemistry \& Behavior, 10, 751-760.

WiSE, R. A. (1982). Neuroleptics and operant behavior: The anhedonia hypothesis. Behavioral \& Brain Sciences, 5, 39-87.

(Manuscript received January 14, 1989.) 